\title{
Adverse Effects of Fast Green, Sodium Nitrate and Glycine on Some Physiological Parameters
}

\author{
Eman G.E. Helal*1, Aisha Almutairi ${ }^{2}$, Mohamed A. Abdelaziz ${ }^{3}$, Asmaa A. H. Mohamed \\ ${ }^{1}$ Department of Zoology, Faculty of Science (Girls), Al-Azhar University, Egypt, \\ ${ }^{2}$ Department of Pediatrics, College of Medicine, Qassim University, Saudi Arabia. \\ ${ }^{3}$ Department of Physiology, Faculty of Medicine (Boys), Al-Azhar University, Egypt \\ *Corresponding Author: Eman Helal, Email: emanhelal@ hotmail.com, \\ Mobile: 00201001025364, orcid.org/0000-0003-0527-7028
}

\begin{abstract}
Background: Food additives are a substance added to food to enhance its flavor or appearance or to preserve it. They are widely used nowadays.

Objectives: The aim of the current work was to determine the hazardous effects of sodium nitrate, fast green and glycine on some physiological parameters such as liver enzymes, lipid profile , hormonal assays ...etc.

Materials and methods: This study has been done on forty male albino rats. The Animals were divided into four groups: Group I (Control untreated group), Group II (fast green-treated group), Group III (glycine-treated group) and Group IV (sodium nitrate-treated group). Estimation of some biochemical parameters (liver enzymes, kidney function tests, glucose, protein profile and lipid profile) and hormonal assays [testosterone, T3 (triiodothyronine), T4 (thyroxine) and insulin were done.

Results: Body weight showed highly significant decreased in both sodium nitrate and fast green. There was an increase in the activities of AST and ALT as well as urea and creatinine, in both sodium nitrate and fast green groups. There was a decrease in plasma proteins in both fast green and sodium nitrate groups. Lipid profile [total cholesterol (TC), triglycerides (TG), very low-density lipoprotein-cholesterol (VLDL-chol) and low-density lipoprotein-cholesterol (LDL-chol)] were decreased in fast green-treated groups while high-density lipoprotein-cholesterol (HDL-chol) was increased. In sodium nitrate group, the lipid profile (TC, TG, VLDL and LDL) were increased while HDL was decreased. Serum glucose, insulin, and HOMA-IR (insulin resistance) were decreased in fast green-treated group and increased in sodium nitrate-treated group. There was a increase in T3 and T4 in fast green-treated group while were decreased in sodium nitrate-treated group. Testosterone decreased in fast green-, glycine- and sodium nitrate-treated groups. While glycine-treated group showed the same results as the control group.
\end{abstract}

Conclusion: It could be concluded that minimizing the use of food additives protects young children and mature people from their destructive effects.

Keywords: Food additives, Thyroid hormones, Glycine, Sodium nitrate, Fast green.

\section{INTRODUCTION}

Food-added substances are those added to food to keep up or improve the safe, newness, taste, surface, or appearance of food. Some food-added substances have been utilized for quite a long time for conservation as salt (in meats, for example, bacon or dried fish), sugar (in jelly), or sulfur dioxide (in wine). A wide range of food-added substances have been created over time to address the issues of food creation, as making food for an enormous scope is totally different from making them at home. Added substances are expected to guarantee handled food stays safe and in great condition all through its excursion from factories or industrial kitchens, during transportation to distribution centers and shops and lastly to customer ${ }^{(1)}$.

The utilization of food-added substances is possibly advocated when their utilization has a technological need, does not mislead customers and serves a very much technological function capacity (for example, to protect the healthful nature of the food or to upgrade the soundness of the food). Food-added substances can be gotten from plants, creatures, minerals or they can be synthetic. They are added deliberately to food to play out certain technological purposes which shoppers frequently underestimate. There are a few thousand food-added substances utilized, which are all intended to make a particular showing in making food more secure or additionally engaging ${ }^{(2)}$.

Fast green (FG) is a bluish green powder totally disintegrated in water. Its chemical structure is $\mathrm{C} 37 \mathrm{H} 34$ $\mathrm{N} 2 \mathrm{Na} 2 \mathrm{OlOS} 3{ }^{(1)}$. Van Hooft mentioned that quick green is one of the manufactured natural food-added substances, utilized as a coloring operator for nourishments, medications, and beautifying agents. It is utilized in coloring drinks, dairy items, puddings, fruits, sugary treats, ice cream, sherbet and baked goods ${ }^{(3)}$.

As of late, the potential job of food-added substances in food prejudice has gotten specific consideration. FG appeared to have harmfulness, altering the quick unfavorably susceptible reaction when ingested orally in food ${ }^{(4)}$, impairing hepatic functions and restraining synaptic action in rat hippocampal interneurons ${ }^{(5)}$. 
Sodium nitrate is the chemical compound with the formula NaNO3. Sodium nitrate is a white solid very soluble in water. It is a readily available source of the nitrate anion (NO3-), which is useful in several reactions carried out on industrial scales for the production of fertilizers, pyrotechnics and smoke bombs, food preservatives (esp. meats) and solid rocket propellant ${ }^{(6)}$. Sodium nitrate is also a foodadditive used as a preservative and color fixative in cured meats and poultry. Studies showed a link between increased levels of nitrates and increased deaths from certain diseases including Alzheimer's disease, diabetes mellitus, stomach cancer and Parkinson's disease possibly through the damaging effect of nitrosamines on DNA. However, little is done to control for other possible causes in the epidemiological results ${ }^{(7)}$. Nitrosamines, formed in cured meats containing sodium nitrate and nitrite, have been linked to gastric cancer and esophageal cancer ${ }^{(8)}$.

Glycine is a colorless, sweet-tasting crystalline solid. Glycine is not basic to the human eating routine, as it is biosynthesized in the body from the amino acid serine, which is gotten from 3-phosphoglycerate. However, the metabolic limit with respect to glycine biosynthesis does not fulfill the requirement for collagen synthesis ${ }^{(9)}$. In the most organisms, the enzyme serine hydroxyl methyltransferase catalyzes this change through the cofactor pyridoxal phosphate. Glycine use is as a flavoring. It additionally has additive properties, may be inferable from its complexation to metal particles. Metal glycinate edifices, for example copper (II) glycinate are utilized as supplements for animal feeds.

The aim of the current work was to determine the hazardous effects of sodium nitrate, fast green and glycine on some physiological parameters such as biochemical parameters (liver enzymes, kidney function tests, glucose, protein profile and lipid profile) and hormonal assays [testosterone, T3 (triiodothyronine), T4 (thyroxine) and insulin.

\section{MATERIALS AND METHODS \\ Ethical approval:}

The study was approved by the Ethics Board of AlAzhar University. This study was conducted in accordance with ethical procedures and policies approved by Animal Care and Use Committee of Faculty of science, Al-Azhar University, Cairo, Egypt.

This study was conducted in Faculty of ScienceAl-Azhar University in the period from November 2019 up to February 2020.

Forty young male albino rats weighing $120-140 \mathrm{~g}$ were utilized in this study. Animals were housed in chrome steel cages and fed rat chow and water ad libitum. The rats were divided randomly into four equal groups (10 rats each). The first group received no treatment and served as control (control untreated), the second group; rats were orally administered with fast green $(12.5 \mathrm{mg} / \mathrm{k} \mathrm{g} \mathrm{b.w./day),} \mathrm{the} \mathrm{third} \mathrm{group;} \mathrm{rats} \mathrm{were}$ orally administrated with glycine $(15 \mathrm{mg} / \mathrm{kg}$ b.w./day) and the fourth group; rats were orally administrated with sodium nitrate ( $5 \mathrm{mg} / \mathrm{kg}$ b.w./day).

Body weight was recorded each week. Following 30 days of treatment, animals were weighed and afterward executed. Blood samples were collected, and sera were separated for biochemical parameters assays immediately.

Biochemical investigations: Total proteins (TP) and albumin concentrations were assessed, and then serum globulins concentration was calculated according to the formula: Globulins $(\mathrm{g} / \mathbf{d l})=$ total proteins $(\mathrm{g} / \mathbf{d l})-$ albumin (g/dl). Aspartate aminotransferase (AST) and alanine aminotransferase (ALT) activities, creatinine, urea, glucose levels as well as lipid profile (total cholesterol, triglycerides and high-density lipoprotein cholesterol (HDL-C)) were determined. All parameters were estimated using BioMerieux SA kits, France. Each ratio of serum albumin/globulins and albumin/creatinine was determined. However, ratios of TC/HDL (risk factor 1) and LDL/HDL (risk factor 2) were also measured after calculation of serum LDL-C (low-density lipoprotein cholesterol) and VLDL (very low density lipoprotein cholesterol) using the Friedwald's equation: LDL $(\mathrm{mg} / \mathrm{dl})=\mathrm{TC}-\{\mathrm{HDL}+$ $[\mathrm{TG} / 5]\}$ and Norbert's equation: $\mathrm{VLDL}=\mathrm{TG} / 5^{(10,11)}$.

Determination of testosterone and thyroid hormones (T3 and T4) were done by an ELISA (Enzyme Linked Immunosorbent Assay) kit (U E Type). Insulin was measured by Biovendor Research and Diagnostic product $^{(12)}$.

HOMA-IR: The approximating equation for insulin resistance, in the early model, used a fasting plasma glucose sample. Then it was measured using insulinglucose product divided by a constant as follows: HOMA -IR = fasting glucose $\mathrm{mg} / \mathrm{dl}$ x Insulin $\mu \mathrm{u} / \mathrm{L} / 405$ fasting glucose in mass units $\mathrm{mg} / \mathrm{dl}$. IR is insulin resistance. Insulin is given in $\mu \mathrm{u} / \mathrm{L}$.

Statistical analysis:

The results were expressed as Mean \pm SEM. Data were analyzed by one-way analysis of variance (ANOVA) and were performed using the Statistical Package (SPSS) program, version 25. The Bonferroni test was used as a method to compare significance between groups.

\section{RESULTS}

In this study, rats showed several signs of behavioral changes like increase in activity, nervous motion and became aggressive to each other. Body weight: rats that received glycine showed insignificant changes in the percentage of body weight, whereas those administrated with fast green group showed a significant decrease in body weight $(\mathrm{P}<0.01)$. Sodium nitrate group showed significant decrease in body weight ( $\mathrm{p}<0.01)$ all as compared to control rats (Table 1). Glucose level: there was significant increases in glucose level in sodium nitrate group $(\mathrm{p}<0.01)$, while 
fast green group showed significant decreases in glucose $(\mathrm{P}<0.01)$, but glycine group showed insignificant changes all in comparison with the control group. There was a highly significant increase in insulin value and HOMA-IR ratio $(\mathrm{p}<0.01)$ in sodium nitrate group, while there was insignificant change in glycine group as compared to control group. The fast greenadministrated group showed significant decrease in insulin and HOMA-IR ratio $(\mathrm{p}<0.01)($ Table 1$)$.

\section{Proteins profile:}

In sodium nitrate and fast green groups, the total protein and albumin levels were significantly decrease $(\mathrm{p}<0.01)$. While they were insignificantly changed in glycine group. Meanwhile, as compared to the control group the all treated groups showed insignificant changes in globulin and albumin/globulin ratio (Table 2).

Liver function tests: AST and ALT activities revealed a highly significant increase in sodium nitrate and fast green groups as compared to the control group ( $\mathrm{p}<$ 0.01 ). Besides, glycine showed significant change in AST and ALT value $(\mathrm{p}<0.05)$ as shown in table (3).
Kidney function tests: There was a highly significant increase in urea and creatinine values in fast green and sodium nitrate groups $(p<0.01)$, while there was insignificant change in urea and creatinine levels in glycine-treated group (Table 4). Lipid profile: There was a highly significant increases in total cholesterol, triglycerides, LDLC, VLDL LDL/HDL and TC/HDL (p $<0.01$ ), while there was a highly significant decrease in HDL level in sodium nitrate group as compared to control rats. There was a highly significant decreases in total cholesterol, triglycerides, LDLC, VLDL LDL/HDL and TC/HDL $(p<0.01)$, while there was a highly significant increase in HDL level in fast greentreated group (Table 5)

Hormones: glycine-, fast green- and sodium nitratetreated groups showed significant decrease in testosterone level. Sodium nitrate group recorded a highly significant decrease in T3 and T4 level (p < 0.01 ), but fast green group recorded a highly significant increase in T3 and T4 level ( $<$ 0.01) as compared to control rats. Glycine group showed insignificant change in T3 and T4 level $(\mathrm{p}<0.01)$ (Table 6).

Table (1): Body weight change (BWC), glucose, insulin hormone and HOMA -IR in control, fast green-, glycine- and sodium nitrate-treated animals

\begin{tabular}{|c|c|c|c|c|}
\hline Group & Control & Fast green & Glycine & Sodium nitrate \\
\hline BWC $(\mathrm{g})$ & $35.78 \pm 0.59$ & $30.21 \pm .68^{* *}$ & $34.80 \pm 1.52$ & $32.00 \pm 0.70^{* *}$ \\
\hline \% of change & & $-24.65 \%$ & $-2.73 \%$ & $-10.56 \%$ \\
\hline Glucose $(\mathrm{mg} / \mathrm{dl})$ & $75.40 \pm 0.70$ & $71.20 \pm 0.73^{* *}$ & $74.10 \pm 0.13$ & $80.16 \pm 0.66^{* *}$ \\
\hline \% of change & & $-5.57 \%$ & $-1.72 \%$ & $6.31 \%$ \\
\hline Insulin $(\mathrm{ng} / \mathrm{dl})$ & $4.04 \pm 0.06$ & $3.84 \pm 0.05^{*}$ & $4.17 \pm 0.07$ & $5.30 \pm 0.20^{* *}$ \\
\hline \% of change & & $-4.95 \%$ & $3.21 \%$ & $31.18 \%$ \\
\hline HOMA-IR (ng/dl) & $0.74 \pm 0.01$ & $0.67 \pm 0.01^{* *}$ & $0.77 \pm 0.01$ & $1.04 \pm 0.04^{* *}$ \\
\hline \% of change & & $-9.45 \%$ & $4.05 \%$ & $40.54 \%$ \\
\hline
\end{tabular}

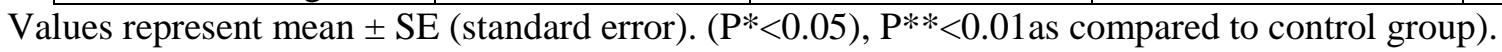

Table (2): Total proteins, albumin, globulins and albumin/ globulins ratio in control, fast green-, glycine- and sodium nitrate-treated animals.

\begin{tabular}{|c|c|c|c|c|}
\hline Group & Control & Fast green & Glycine & Sodium nitrate \\
\hline Total proteins $(\mathrm{g} / \mathrm{dl})$ & $6.18 \pm 0.08$ & $5.87 \pm 0.18$ & $6.70 \pm 0.18^{*}$ & $5.25 \pm 0.16^{* *}$ \\
\hline$\%$ of change & & $-5.01 \%$ & $8.41 \%$ & $-15.04 \%$ \\
\hline Albumin $(\mathrm{g} / \mathrm{dl})$ & $3.44 \pm 0.03$ & $3.19 \pm 0.08^{* *}$ & $3.90 \pm 0.03^{* *}$ & $2.82 \pm 0.18^{* *}$ \\
\hline$\%$ of change & & $-7.26 \%$ & $13.37 \%$ & $-18.02 \%$ \\
\hline Globulins $(\mathrm{g} / \mathrm{dl})$ & $2.74 \pm 0.11$ & $2.68 \pm 0.24$ & $2.80 \pm 0.15$ & $2.43 \pm 0.20$ \\
\hline \% of change & & $-2.18 \%$ & $2.18 \%$ & $-11.31 \%$ \\
\hline Albumin/Globulins & $1.26 \pm 0.06$ & $1.25 \pm 0.18$ & $1.40 \pm 0.08$ & $1.22 \pm 0.19$ \\
\hline$\%$ of change & & $-0.79 \%$ & $11.11 \%$ & $-3.17 \%$ \\
\hline
\end{tabular}

Values represent mean \pm SE (standard error). ( $\left.\mathrm{P}^{*}<0.05\right)$, $\mathrm{P} * *<0.01$ as compared to control group).

Table (3): Alanine transaminase and aspartic transaminase, in control, fast green-, glycine- and sodium nitrate-treated animals.

\begin{tabular}{|c|c|c|c|c|}
\hline Group & Control & Fast green & Glycine & Sodium nitrate \\
\hline ALT (IU/L) & $22.98 \pm 0.47$ & $31.60 \pm 0.92^{* *}$ & $20.32 \pm 0.53^{*}$ & $33.30 \pm 1.65^{* *}$ \\
\hline \% of change & & $37.51 \%$ & $-11.57 \%$ & $44.90 \%$ \\
\hline AST e (IU/L) & $51.71 \pm 0.31$ & $59.00 \pm 0.70^{* *}$ & $49.60 \pm 0.43^{*}$ & $60.640 \pm 0.89^{* *}$ \\
\hline \% of change & & $14.09 \%$ & $-4.06 \%$ & $17.26 \%$ \\
\hline
\end{tabular}


Table (4): creatinine and urea in control, fast green-, glycine- and sodium nitrate-treated animals.

\begin{tabular}{|c|c|c|c|c|}
\hline Creatinine $(\mathrm{mg} / \mathrm{dl})$ & $0.91 \pm 0.05$ & $1.11 \pm 0.03^{* *}$ & $0.92 \pm 0.05$ & $1.22 \pm 0.19^{* *}$ \\
\hline$\%$ of change & & $21.97 \%$ & $1.09 \%$ & $34.06 \%$ \\
\hline Urea $(\mathrm{mg} / \mathrm{dl})$ & $30.34 \pm 0.53$ & $39.70 \pm 0.48^{* *}$ & $29.56 \pm 0.50$ & $37.58 \pm 0.94^{* *}$ \\
\hline$\%$ of change & & $30.85 \%$ & $-2.57 \%$ & $23.86 \%$ \\
\hline
\end{tabular}

Values represent mean $\pm \mathrm{SE}$ (standard error). ( $\mathrm{P} *<0.05), \mathrm{P}^{* *}<0.01$ as compared to control group).

Table (5): Cholesterol (TC), triglycerides, high-density lipoprotein (HDL), low-density lipoprotein (LDL), very lowdensity lipoprotein (VLDL), LDL/HDL and TC/HDL in control, fast green-, glycine- and sodium nitrate-treated animals

\begin{tabular}{|c|c|c|c|c|}
\hline Group & Control & Fast green & Glycine & Sodium nitrate \\
\hline Cholesterol (mg/dl) & $80.00 \pm 1.14$ & $77.00 \pm 0.70^{*}$ & $79.00 \pm 0.31$ & $86.42 \pm 0.88^{* *}$ \\
\hline \% of change & & $-3.75 \%$ & $-1.25 \%$ & $8.02 \%$ \\
\hline $\begin{array}{c}\text { Triglycerides } \\
\text { (mg/dl) }\end{array}$ & $75.78 \pm 0.36$ & $72.40 \pm 0.67^{*}$ & $75.50 \pm 0.44$ & $80.18 \pm 0.75^{* *}$ \\
\hline \% of change & & $-4.48 \%$ & $-0.36 \%$ & $5.80 \%$ \\
\hline HDL (mg/dl) & $43.75 \pm 0.53$ & $47.00 \pm 0.70^{* *}$ & $43.70 \pm 0.37$ & $39.14^{* *} \pm 0.68$ \\
\hline \% of change & & $7.42 \%$ & $-0.11 \%$ & $-10.53 \%$ \\
\hline LDL (mg/dl) & $21.09 \pm 0.78$ & $15.52 \pm 1.01^{* *}$ & $20.20 \pm 0.43$ & $31.24 \pm 0.73^{* *}$ \\
\hline \% of change & & $-26.41 \%$ & $-4.22 \%$ & $48.12 \%$ \\
\hline VLDL (mg/dl) & $15.15 \pm 0.07$ & $14.48 \pm 0.13^{*}$ & $15.10 \pm 0.08$ & $16.03 \pm 0.15^{*}$ \\
\hline$\%$ of change & & $-4.42 \%$ & $-0.33 \%$ & $5.80 \%$ \\
\hline LDL/HDL & $0.48 \pm 0.01$ & $0.33 \pm 0.02^{* *}$ & $0.46 \pm 0.01$ & $0.79 \pm 0.02^{* *}$ \\
\hline$\%$ of change & & $-31.25 \%$ & $-4.16 \%$ & $139.39 \%$ \\
\hline TC/HDL & $1.82 \pm 0.01$ & $1.63 \pm 0.02^{* *}$ & $1.88 \pm 0.01$ & $2.19 \pm 0.02^{* *}$ \\
\hline \% of change & & $-10.43 \%$ & $3.29 \%$ & $34.35 \%$ \\
\hline
\end{tabular}

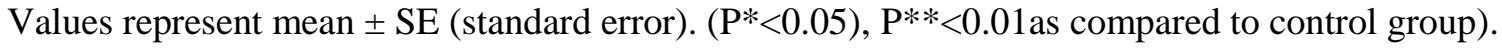

Table (6): Tri-iodothyronin $\left(\mathrm{T}_{3}\right)$, thyroxine $\left(\mathrm{T}_{4}\right)$ and testosterone hormones in control, fast green, glycine and sodium nitrate treated animals

\begin{tabular}{|c|c|c|c|c|}
\hline Group & Control & Fast green & Glycine & Sodium nitrate \\
\hline $\mathrm{T}_{3}$ hormone $(\mathrm{ng} / \mathrm{dl})$ & $108.22 \pm 0.83$ & $118.5 \pm 1.28^{* *}$ & $107.08 \pm 0.25$ & $94.67 \pm 2.79^{* *}$ \\
\hline$\%$ of change & & $9.44 \%$ & $-1.05 \%$ & $-9.49 \%$ \\
\hline $\mathrm{T}_{4}$ hormone $(\mathrm{ng} / \mathrm{dl})$ & $4.57 \pm 0.15$ & $7.63 \pm .59^{* *}$ & $4.49 \pm 0.06$ & $2.81 \pm 0.15^{* *}$ \\
\hline$\%$ of change & & $13.78 \%$ & $-1.75 \%$ & $-66.95 \%$ \\
\hline $\begin{array}{c}\text { Testosterone hormone } \\
\text { (ng/dl) }\end{array}$ & $57.30 \pm 0.42$ & $53.84 \pm 0.87^{*}$ & $49.48^{* *} \pm 0.47$ & $42.80 \pm 0.86^{* *}$ \\
\hline$\%$ of change & & $-6.03 \%$ & $-13.64 \%$ & $-25.30 \%$ \\
\hline
\end{tabular}

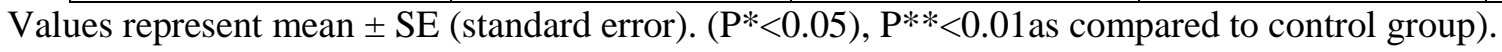

\section{DISCUSSION}

After administration of all food additives used (Fast green, glycine and sodium nitrate), the aim of this study was to determine the side effects of these food additives on some physiological parameters in male albino rats. Fast green is a synthetic organic food dye, administered to albino rats for 35 days produced harmful changes in the studied blood parameters. However, fast green group recorded a highly significant decrease in the body weight. Similar finding was recorded in Abou El- Zahab et al. ${ }^{(12)}$ who stated that synthetic food colorants cause a reduction in body weight. Our results stated that nitrate could induce body weight loss by the way of inhibiting food intake through its influence on the nervous regulation of feeding behavior that was found to cause a decrease of growth hormone receptors within the liver. Thus, causing lack of plasma somatomedins and in turn affect body growth (13). Our result stated that a general decrease in serum glucose level, insulin and insulin resistance (HOMAIR) in albino rats in response to fast green oral administration that could be attributed to impairing hepatic functions ${ }^{(5)}$. Fast green may indirectly play a role in carbohydrate metabolism.

Our results clearly showed in the NaNO3-treated rats, a significant increase in serum glucose insulin and insulin resistance (HOMA-IR) concentration. Shelpov et al. ${ }^{(14)}$ reported that in the presence of nitrate ions, the activity of amylase and phosphorylase increases leading to liberation of glucose from glycogen, so blood glucose increases while liver glycogen decreases. Other findings suggested a stimulation of gluconeogenesis by nitrate and glucose shift from tissue to blood or an impairment of glucose mobilization ${ }^{(15)}$. We can expect that nitrate 
produces hyperglycemia due to decrease in the release of insulin. It is known that nitric oxide is formed from nitrate at least by the vascular epithelial cells ${ }^{(16)}$. Both nitric oxide and nitrate decreases intracellular calcium through open potassium channels, which close calcium channels. Calcium is known to trigger insulin secretion and calcium channel blockers lead to hyperglycemia ${ }^{(17)}$. Furthermore, nitroso-compounds alter the antioxidant system leading to disturbance in the metabolic processes ending by hyperglycemia ${ }^{(17)}$.

Our results stated that there was a significant decreased in the levels of total proteins in the fast greentreated rats that could be attributed to an increase in amino acids deamination because of the presence of some toxic compounds ${ }^{(18)}$. In sodium nitrate-treated group, there was a decrease in total proteins due to deficiency in food intake. In addition, the reduction in total protein level may result to nitrate toxicity mediated via formation of nitric oxide or peroxynitrite, which oxidizes proteins and lipoproteins. In another way, decreased protein content in response to nitrate exposure may prompt to the harmful side effect of nitrite (the active metabolite). Previous studies confirmed this hypothesis that the nitrite effect is reflected in the biosynthesis of proteins ${ }^{(19)}$. It was found that serum proteins of rats are decreased due to the toxic effect of nitrate on the thyroid and adrenal glands leading to block of protein synthesis, while fast breakdown occurs due to an increase of free amino acids and due to a decrease of protein turnover. It is clear that the total serum protein decreases by nitrate mainly via its effects on the liver, either through the necrotic changes, especially of the plasma membrane, or via the inhibition of the oxidative phosphorylation process and the availability of energy source for protein synthesis and other metabolic processes ${ }^{(20)}$.

Our results showed in fast green-treated group that the transaminases (AST and ALT) showed functional activity of liver. As the fast green causes hepatotoxic effects, there was a general increase in the activities of these enzymes in treated rats compared to the control. The observed elevation in serum AST and ALT activities in response to fast green administration is in agreement with the study of Mekkaway $\boldsymbol{e t}$ al. ${ }^{\text {(21) }}$ who found that activities of AST, ALT and ALP were increased significantly following fast green treatment to rats. The liver enzymes are normally found in circulation in small amounts; however, increase in AST levels can occur in relation with damages of heart or skeletal muscle as well as of liver parenchyma ${ }^{(22)}$. Consequently, elevated activities of ALT and AST observed in the current study in response to fast green administration could be a common sign of impaired liver function. In our work, there was an increase of serum ALT, AST activities suggesting hepatic damage and change of its function. These enzymes cited above are the most sensitive biomarkers directly implicated in the extent of hepatotoxicity because they are intracellular enzymes and are released into the circulation after cellular damage ${ }^{(23)}$. Increased activity in these enzymes in serum of NaNO3-treated rats might be due to the necrosis in the hepatic tissues and an alteration of membrane permeability. Earlier findings reported the increase in the level of AST, ALT and LDL in sodium nitrate-treated rats due to the formation of free radical $\mathrm{ONOO}^{-}$from nitric oxide. Both $\mathrm{NO}$ and oxygen radicals could react further to produce other oxidants and nitro compounds such as peroxynitrite to induce liver injury and to play a role in death of liver cells ${ }^{(24)}$.

Our results showed that there was a general increase in urea and creatinine in fast green-treated group due to enhanced protein catabolism and accelerated amino acid deamination for gluconeogenesis, which is possibly an acceptable postulate to interpret the elevated levels of urea ${ }^{(25)}$. Uric acid is the end product of the catabolism of tissue nucleic acid, i.e. purine bases metabolism ${ }^{(26)}$. The elevations in uric acid levels might be due to degradation of purines or an increase of uric acid levels by either overproduction or inability of excretion (26). The elevations in creatinine level in response to fast green intake agrees with that observed by Mekkaway et al. ${ }^{(21)}$. Creatinine appears in serum in amounts proportional to the body's muscles mass and is more readily excreted by the kidneys than urea and uric acid (27). Elevated creatinine concentration is associated with abnormal renal (glomerular) function ${ }^{(25)}$. Our results stated that there were high levels of urea and creatinine in both serum and urine of nitrate-exposed rats, however an increased urinary protein loss was also found. This protein loss probably resulting from nitrate-induced kidney dysfunction ${ }^{(28)}$.

Our results demonstrated that triglycerides and total cholesterol levels were decreased in response to fast green administration. The possible explanation of these observed decrements may reside in direct and indirect action of fast green on lipid metabolism or lipid peroxidation ${ }^{(29)}$. Our results showed a marked increase of serum total cholesterol and triglyceride levels in rats but LDL-C levels and atherogenic index were enhanced, while HDL-C decreased after nitrate treatment. These results are consistent with previous findings realized on nitrate administered to adult rats ${ }^{(30)}$. In addition, we noticed an increase in T4 and T3 in fast green-treated rats. However, due to negative feedback mechanism, increased level of T4 and T3 led to reduced production of TSH from the pituitary ${ }^{(31)}$. The increase in T3 could also be due to peripheral conversion of $\mathrm{T} 4$ to $\mathrm{T} 3 \mathrm{vis}-$ a-vis increase of the parenchymal cells of the liver because of the presence of reactive oxygen species during the bio- transformation of the dye. In this regard, a number of studies have been focused on the effect of nitrate on the thyroid functions. Some showed thyroid hypertrophy with decreased thyroid hormone levels in people who consumed drinking water with nitrate levels below or above the WHO nitrate standard of $50 \mathrm{mg} / \mathrm{L}$. According to Luboshitzky et al. ${ }^{\left({ }^{(32)}\right.}$ sub- 
clinical hypothyroidism, which is characterized by a decreased FT4 and an increased TSH, was also associated with elevated total cholesterol, LDL-C and serum triglyceride concentrations due to a reduced removal rate from plasma in such case. In our work, sodium nitrate decreased the thyroid hormone T3and T4 this because nitrate acts as a dose-dependent competitive inhibitor of the sodium iodide symporter (NIS). Sufficiently diminished iodine uptake by the thyroid may result in decreased production of thyroid hormones, which leads to increased release of TSH from the anterior pituitary gland and consequently increased uptake of iodine by the thyroid gland. Concern for nitrate-induced effects on thyroid function has prompted scientists to perform studies designed to assess thyroid function relative to drinking water and/or dietary nitrate levels. Available human data suggest that elevated levels of nitrate in drinking water and/or diets may causes signs of thyroid dysfunction. However, limitations of these studies included lack of individual dose-response data, quantification of iodine intake, and control for other potential substances that may affect the thyroid.

Our results stated that sodium nitrate decreased testosterone hormone and this testosterone produced in the interstitial cells of Leydig is a prerequisite for the maintenance of established spermatogenesis ${ }^{(33)}$. The reduced cellularity of the interstitium in the testes of the rats treated with nitrate alone might produce a decrease in testosterone and consequently poor spermatogenesis. Our results are in agreement with those observed by Ashour and Abdelaziz who stated that albino rats' exposure to $125 \mathrm{mg} / \mathrm{kg} /$ day of fast green, a synthetic organic food additive similar to tartrazine, for 35 days, can provoke a significant decrease in cholesterol level in serum ${ }^{(34)}$. Taken together, our findings showed that fast green had many harmful effects on spermatogenesis and steroidogenesis in rat. It is a fact that testosterone is an essential factor controlling testicular development and sperm apoptosis. A lower concentration of this indispensable androgen is usually associated to a decrease in Leydig cells activity or to a lower testosterone capture in testis. As we know, testosterone is necessary to maintain a normal fertilizing ability and sperm maturation is a testosterone dependent process ${ }^{(35)}$. A low testosterone level in testis, principally induce an excessive sperm apoptosis and consequently diminish sperm survival. Our results demonstrated that serum testosterone levels were reduced in rats treated with glycine. Glycine is one of the food additives used as a flavour and it was reported that the central nervous system of glycine-treated rats showed neurogenic functional changes in the hypothalamus that induced a reduction in levels of $\mathrm{LH}, \mathrm{FSH}$ and testosterone. Moreover, it was reported that glycine destroyed neurons of the hypothalamus in rats. Such neuronal losses in the hypothalamus can result in disruption of the hypothalamic-pituitary-testis regulatory axis that controls the steroidogenesis of testicular Leydig cells
(35). This will lead to decrease of serum testosterone levels as recorded in the present work.

\section{CONCLUSION}

It could be concluded that minimizing the use of food additives protects young children and mature people from their destructive effects.

\section{REFERENCES}

1. Moeen S S, Elhalwagy M E, Ayaz N O (2018): Alterations in Oxidative Stress and Antioxidantin Albino rats Treated with Individual and CombinedVarious Food Additives. Int. J. Adv. Res. Bio Sci., 5: 118-123.

2. Helal E G, El-Sayed R A, El-Gamal M S (2017): Assessment of the Physiological Changes Induced by Sodium Nitrite, Annatto or Mono Sodium Glutamate in Male Albino Rats. Egyptian Journal of Hospital Medicine, 67: 330- 335

3. Van Hooft JA (2002): Fast Green FCF (Food Green 3) inhibits synaptic activity in rat hippocampal interneurons. Neurosci.Lett., 318 (3): 163-165 .

4. Tanaka Y et al. (1995): Effects of synthetic food colors on $[-3 \mathrm{H}]$ serotonin release from rat basophilic leukemia cells (RBL-2H3). Japan. J. Toxicol. Environ. Health, 41: 206211

5. Ashida H et al. (2000): Synergistic effects of food colors on the toxicity of 3-amino-1,4 dimethyl-5H-pyrido[4,3-b] indole (Trp-P-1) in primary cultured rat hepatocytes. J. Nutr. Sci.Vitaminol, 46 (3): 130-136

6. Baekeland S H (1914): Några sidor af den kemiska industrien. Svensk Kemisk Tidskrift, Pp: 140

7. De La Monte SM, Neusner A, Chu J, Lawton M (2009): "Epidemilogical trends strongly suggest exposures as etiologic agents in the pathogenesis of sporadic Alzheimer's disease, diabetes mellitus, and nonalcoholic steatohepatitis". Journal of Alzheimer's Disease, 17 (3): 519-29.

8. Jakszyn, Paula, Gonzalez, Carlos A (2006): Nitrosamine and related food intake and gastric and oesophageal cancer risk: a systematic review of the epidemiological evidence. World Journal of Gastroenterology, 12 (27): 4296-4303.

9. Meléndez-Hevia 9 E, De Paz-Lugo P, Cornish-Bowden A, Cárdenas M L (2009): A weak link in metabolism: the metabolic Capacity for glycine biosynthesis does not satisfy the need for collagen synthesis. Journal of Biosciences, 34 (6): 853-72.

10. Norbert W T (1995): Clinical guide to laboratory tests. 3rd ed. Saunders W. B., Company, Philadelphi.

11. Friedewald W T, Levy R I, Fredrickson D S (1972): Estimation of the concentration of low-density lipoprotein cholesterol in plasma, without use of the preparative ultracentrifuge. Clinical chemistry, 18: 499-502

12. Abou El - Zahab HSH, EI - Khyat ZA, Awadallah R et al. (1997): Physiological effects of some synthetic food coloring additives on rats. Boll Chim Farm., 136 (10): 615-627.

13. Jahreis G, Sch Z 1z (1987):Growth impairment caused by dietary nitrate intake regulated via hypothyroidism and decreased https://pubmed.ncbi.nlm.nih.gov/3499306/

14. Shelpov V, Chekulaev V, Pasha-Zade G (1991): Factors within the body determining the glycogen reserves in the tissues of rats. Biomed Sci., 2: 111-20. 
15. Wiechetek M, Garwacki S, Karlik W (1993): et al. Effect of nitrite on ureagenesis and carbohydrate metabolism in isolated rat hepatocytes. Arch Environ ContamToxicol., 24, 375-80.

16. Katzung BG (1995): Basic and clinical pharmacology. A long medical book, 6th ed., less Altes. California, Pp: 199203.

17. Anil KB, Manju B, Giridhar S et al. (2005): Protective role of Vitamin E pre-treatment on $\mathrm{N}$-nitrosodiethylamine induced oxidative stress in rat liver. Chem Biol Interact., 156: 101-11.

18. Varley H (1987): Practical clinical Biochemistry, 6th ed. https://www.amazon.com/Practical-Clinical-Biochemistry-

H-Varley/dp/0433338067

19. Helal EG (2001): Progressive effects of the interaction of sodium nitrite and sunset yellow on different physiological parameters in albino rats. Egypt $\mathbf{J}$ Hospit Med., 2: 23-46.

20. Anthony ML, Gartland KP, Beddell CR et al. (1994): Studies on the biochemical toxicology of uranyl nitrate in the rat. Arch Toxicol., 68: 43-53.

21. Mekkawy HA et al. (1998) Toxic effect of synthetic and natural food dyes on renal and hepatic functions in rats. Toxicol. Lett., 95: 155-155.

22. Moss DW, Henderson AR (1999) : Clinical Enzymology in: Textbook of clinical chemistry 3rd ed. Philadelphia, WB Saunders Company. Pp: 617-721.

23. El-Sharaky AS, Newairy AA, Badreldeen MM et al. (2007): Protective role of selenium against renal toxicity induced by cadmium in rats. Toxicology, 235: 185-93.

24. Teppema LJ, Nieuwenhuijs D, Sarton E et al. (2002): Antioxidants prevent depression of the acute hypoxic ventilatory response by subanaesthetic halothane in men. https://www.ncbi.nlm.nih.gov/pmc/articles/PMC229063 9/
25. Bishop LM (2004): Clinical chemistry principles, Procedures, correlations.5th ed. Lippincoh Williams and Wilkins, Philadelphia, Hong Kong. Pp: 220-253

26. Wolf PL (1972): Methods and Techniques in clinical chemistry. Wiley - Interscience a division of John Wiley and Sons., New York, London, Sydney, Toronto.

27. Stryer L (1995): Biochemistry.4th ed. WH Freeman and Company, New York, USA, Chapter 24, Pp: 607-610

28. Al-Ayed M I (2000): Toxicity of drinking water with different nitrate levels. J. Egypt. Ger. Soc. Zool., 31 (A): 197- 171-180-209

29. Berne MR, Levy NM (1998): Physiology. Fourth ed., Mosby, New York, Pp: 910-929

30. Tajtakova M, Semanova $Z$, Tomkova $Z$ et al. (2006): Increased thyroid volume and frequency of thyroid disorders signs in schoolchildren from nitrate-polluted area. https://pubmed.ncbi.nlm.nih.gov/16095667/

31. Crook AM (2007): Thyroid Function. In Clinical Chemistry and Metabolic Medicine. $7^{\text {th }}$ edition, Hodder Arnold publishers, London, Pp: 162 -173

32. Luboshitzky R, Aviv A, Herer P (2002): Risk factors for cardiovascular disease in women with subclinical hypothyroidism. Thyroid, 12: 421-5.

33. Eskiocak S, Dundar C, Basoglu T et al. (2005):The Effects of taking chronic nitrate by drinking water on thyroid functions and morphology. Clin Exp Med., 5: 6671.

34. Ashour A A, Abdelaziz, I (2009): Role of fast green on the blood of rat and the therapeutic action of vitamin $\mathrm{C}$ or E. https://www.semanticscholar.org/paper/Role-of-fastgreen-on-the-blood-of-rats-and-the-of-AshourAbdelAziz/681a7e653ed7da243b3f5881bf5e406af06054 93

35. InZirkin BR (1998): Spermatogenesis: its regulation by testosterone and FSH. Semin Cell Dev Biol., 9: 417- 21 